\title{
A Dimensional Analysis of Solids Transport and Dispersion in a Rotary Kiln
}

\author{
M. E. Whatley
}

\section{MASIER}

\section{OAK RIDGE NATIONAL LABORATORY}




\section{DISCLAIMER}

This report was prepared as an account of work sponsored by an agency of the United States Government. Neither the United States Government nor any agency Thereof, nor any of their employees, makes any warranty, express or implied, or assumes any legal liability or responsibility for the accuracy, completeness, or usefulness of any information, apparatus, product, or process disclosed, or represents that its use would not infringe privately owned rights. Reference herein to any specific commercial product, process, or service by trade name, trademark, manufacturer, or otherwise does not necessarily constitute or imply its endorsement, recommendation, or favoring by the United States Government or any agency thereof. The views and opinions of authors expressed herein do not necessarily state or reflect those of the United States Government or any agency thereof. 


\section{DISCLAIMER}

Portions of this document may be illegible in electronic image products. Images are produced from the best available original document. 
This report was prepared as an account of work sponsored by the United States Government. Neither the United States nor the Energy Research and Development Administration/United States Nuclear Regulatory Commission, nor any of their employees, nor any of their contractors, subcontractors, or their employees, makes any warranty, express or implied, or assumes any legal liability or responsibility for the accuracy, completeness or usefulness of any information, apparatus, product or process disclosed, or represents that its use would not infringe privately owned rights. 
ORNL/TM- 5898

Contract No. W-7405-eng-26

ADVANCED FUEL RECYCLE PROGRAM

A DIMENSIONAL ANALYSIS OF SOLIDS TRANSPORT

AND DISPERSION IN A ROTARY KILN

M. E. Whatley

Chemical Technology Division

Date Published - July 1977

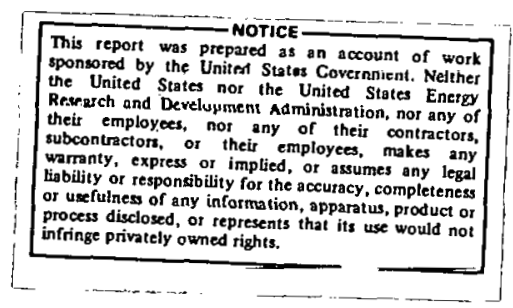

NOTICE This document contains information of a preliminary nature. It is subject to revision or correctlon and therefore does not represent a final report.

\author{
OAK RIDGE NATIONAL LABORATORY \\ Oak RIdge, Tennessee 37830 \\ operated by \\ UNION CARBIDE CORPORATION \\ for the \\ ENERGY RESEARCH AND DEVELOPMENT ADMINISTRATION
}


THIS PAGE

WAS INTENTIONALLY

LEFT BLANK 
Summary- 1

Comments on the Technique 1

Attack on the Problem- 3

The Computer Output-... 4

Significance of Results-_. 9

A Different Problem-10 
A DIMENSIONAL ANALYSIS OF SOLIDS TRANSPORT

AND DISPERSION IN A ROTARY KILN

M. E. Whatley

SUMMARY

To organize data being obtained in an existing experimental program on the dispersion coefficient for material in a rotating kiln, a dimensional analysis was performed using all of the variables now thought to be relevant. Rotary kilns are being considered for use in the voloxidation process for the recovery of tritium from spent nuclear power reactor fuels. Design for the efficient recovery of tritium stipulates a residence time distribution for material within the kiln; therefore, a consideration of material dispersion is important.

The study revealed that the system is fairly tightly constrained. of all possible dimensionless groups formed from the process variables, only three remained after those groups consisting of ratios of length were extracted and allowance was made for implicit relations among variables.

The set that describes the system includes the velocity number, the Watt number, and the fraction of the kiln filled with solids. Since the velocity number divided by the operating slope of the kiln behaves as a constant (at least for first-order effects), the program should correlate the Watt number with fraction full and the dimensionless numbers that relate the geometry of the system, including size of the feed material and flight dimensions.

\section{COMMENTS ON THE TECHIVIQUE}

Dimensional analysis has been used by chemical engineers for many decades and has been valuable in several areas. Through the identification of important dimensionless groups, this technique permits a generalized presentation of lata. Of equal importance, however, are the implications generated from the analysis regarding the degrees of freedom in an experimental system. When all of the dependent and independent variables necessary to describe the system and the consequent number of. 
dimensions are identified, a set of dimensionless groups, Pi terms, can be developed through a formal procedure known as the Buckingham Pi method. These groups form a sufficient set to express all functional relationships. No more terms than those derived from the analysis are required. If the set is inadequate to correlate effects, important variables exist beyond those included. The use of more terms than those prescribed for the same set of variables results in confusing redundancy.

The method does not necessarily yield a unique set of Pi terms, since products and quotients of members of any set can be used to generate new equivalent sets. Some sets are more useful than others because they include the more accessible variables in a handier form or are more amenable to physical interpretation.

A few rules for the application of dimensional analysis will yield simpler and more meaningful results. Variables with identical dimensional structure, such as length and width, will generate Pi terms that are simple ratios. In this case, the implicit $\mathrm{Pi}$ term can be omitted along with one of the variables that form the ratio. Where implicit equations relate subsets of variables, $P i$ terms that state these equations will be generated. If rim velocity, rotational rate, and the radius of a wheel were included in an analysis, a Pi term would consist of the ratio of the rim velocity to the product of the rotational rate and the radius. The confusion of generating such constant, and therefore trivial, Pi terms can be avoided by eliminating one of the variables from the analysis.

Dimensional analysis does not relate Pi terms functionally. It seems, however, to be a common misconception among engineers that there is some fundamental basis for writing

$$
\mathrm{Pi}_{1}=\mathrm{Pi}_{2}^{\mathrm{a}} \mathrm{Pi}_{3}^{\mathrm{b}} \mathrm{Pi}_{4}^{\mathrm{c}} \ldots
$$

Those familiar with computers might feed large blocks of data into regression routines to calculate values of a, b, c, etc., along with correlation coefficients and confidence limits. However, the use of sophisticated computational devices cannot improve the inherently empirical nature of the expression. The application of dimensional analysis that gave us the Reynolds number and Fanning friction factor from fluid dynamics illustrates the inadequacy of this approach. 
ATTACK ON THE PROBLEM

Solids transport in a rotary kiln was analyzed by the Buckingham Pi method using a computer program developed by the author in collaboration with Susan K. Whatley. This program accepts as input the names and dimensions of included variables and generates the Pi terms (dimensionless groups) by which the system can be described. The program actually permutes the variables to produce several sets of Pi terms, any one set of which is sufficient and capable of producing any other set by multiples or quotients of its members. This multiplicity eases the task of finding the most convenient set to use.

The analysis was conducted in two steps to reach a minimum number of $\mathrm{Pi}$ terms and to call attention to the assumptions and limitations of the process. First, all of the variables thought to be significant were included without regard to redundancy. The slope of the kiln, although used in data correlation, was excluded from the dimensional analysis because it is already a dimensionless number - a Pi term.

The dimensions included were mass $(M)$, length $(L)$, and time $(T)$. The variables are discussed below:

- Diameter refers to the inside diameter of the kiln and was used as the reference length variable where possible.

- Length refers to the length of the kiln in which solids are found.

- Flight size is twice the protrusion of a flight inside the kiln (to properly relate to kiln diameter). Flights are assumed as parallel with the axis of the kiln and simple in structure. The number of flights is a dimensionless number that could be considered a Pi term, but was not included in this analysis.

- Feed size is a characteristic dimension of the feed particles. The feed actually has a size distribution that could be important. For this analysis, however, only a single number is used.

- Feed rate is the mass rate of feed to the kiln, which is the rate of mass progression through the kiln at steady state.

- Rotation can ref'er to the revolutions per minute of the kiln or its angular velocily. Cunversion faciors are not relevant to the analysis. 
- Velocity is the linear rate of progression of material through the kiln.

- Bulk Density is the mass per unit volume of settled solids in the kiln.

- Holdup in the first step of the analysis is the total mass of material in the kiln. In subsequent steps, the holdup is a function of length and becomes the mass of solids per unit of length of kiln.

- Dispersion refers to the dispersion coefficient used to characterize axial mixing.

Since this is a steady-state analysis, time is not a variable.

Although additional variables could be identified, and the ones listed could be more precisely defined, this list, which includes all first-order effects, is practical for an experimental program. The variables and dimensions are summarized in Table 1.

THE COMPUTER OUIPUI'

Discussion of the analysis is best approached by anticipating the results and by identifying several groups that will be found. These groups will sometimes appear in reciprocal form or be raised to powers other than unity.

$$
\begin{aligned}
& \text { Dispersion number }=\frac{\text { Dispersion coefficient }}{(\text { Kiln length)(Velocity })} \\
& \text { Watt number }=\frac{\text { Dispersion coefficient }}{\text { (Rotation rate) (Diameter })} \\
& \text { Velocity number }=\frac{\text { Velocity }}{\text { (Rotation rate) (Diameter })}
\end{aligned}
$$

Table 2 shows a typical set of $\mathrm{Pi}$ terms generated by the analysis. This set, selected from a group of 13 on the basis of its usefulness, shows that ten variables and three dimensions produce seven Pi terms. Theref'ore, a complete description of the system requires the consideration of seven groups. A close look, however, quickly reveals a simplification. Since diameter, length, flight size, and feed size have the dimension length, three of the seven $H i$ terms consist of ratios of palrs of these. If all dimensions increase by the same factor, a single number quantifies the effect, and variation of the dimension of any structural feature requires its own P1 term. 
TABLE 1. Dimensions of variables from the general case

\begin{tabular}{lccc}
\hline Variable & Mass & Length & Time \\
\hline Diameter & 0 & 1 & 0 \\
Length & 0 & 1 & 0 \\
Holdup & 1 & 0 & 0 \\
Feed Rate & 1 & 0 & -1 \\
Rotation & 0 & 0 & -1 \\
Feed Size & 0 & 1 & 0 \\
Dispersion & 0 & 2 & -1 \\
Velocity & 0 & 1 & -1 \\
Bulk Density & 1 & -3 & 0 \\
Flight Size & 0 & 1 & 0 \\
\hline
\end{tabular}

TABLE 2. Pi terms from the general case

\begin{tabular}{|c|c|c|c|c|c|c|c|}
\hline Variable & 1 & 2 & 3 & 4 & 5 & 6 & 7 \\
\hline Length & 1.0 & & & & & & \\
\hline Feed Size & & 1.0 & & & & & \\
\hline Velocity & & & 1.0 & & & & \\
\hline Feed Rate & & & & 1.0 & & & \\
\hline $\begin{array}{l}\text { Flight Size } \\
\text { Rotation }\end{array}$ & & & & & 1.0 & 1.0 & \\
\hline Bulk Density & & & & & & & 1.0 \\
\hline $\begin{array}{l}\text { Diameter } \\
\text { Dispersion } \\
\text { Holdup }\end{array}$ & -1.0 & -1.0 & $\begin{array}{r}1.0 \\
-1.0\end{array}$ & $\begin{array}{r}2.0 \\
-1.0 \\
-1.0\end{array}$ & -1.0 & $\begin{array}{r}2.0 \\
-1.0\end{array}$ & $\begin{array}{r}3.0 \\
-1.0\end{array}$ \\
\hline
\end{tabular}


$\mathrm{Pi}(3)$ is recognized as the watt number and $\mathrm{Pi}(5)$ is the velocity number. $P i(4)$, which includes the holdup, seems to have little utility. The diameter cubed' could, however, be replaced by the diameter squared times the length, which with appropriate constants becomes the volume of the kiln. In this form, $\mathrm{Pi}(4)$ is the fraction of the kiln volume occupied by solids and is a useful group. The remaining group, Pi(7), can be similarly interpreted. If diameter cubed is taken as volume, this group becomes a dimensionless feed rate and conveniently contains only independent variables.

This set of Pi terms could be used as the basis for an experimental program but is more complicated than necessary because the inherent relationship between feed rate, holdup, and progression velocity is not utilized. Additionally, this set does not contain groups useful for somc analyses.

Table 3 shows another set of Pi terms produced by the same calculation. Because of the reordering of the variables, kiln length instead of diameter appears in more of the terms. Three of the seven terms are again devoted to ratios of length. The reciprocal dispersion number is $\mathrm{Pi}(2)$, and the reciprocal watt number is $\mathrm{Pi}(6)$; kiln length instead of diameter is used. $\mathrm{Pi}(7)$ is reciprocal fraction full if length cubed is properly interpreted. $\mathrm{Pi}(4)$ presents a problem in interpretation. It might be factored into:

$$
\mathrm{Pi}(4)=\left[\frac{(\text { Velocity) (Kiln length) }}{\text { (Dispersion coefficient) }}\right]\left[\frac{(\text { Feed rate) (Kiln length) }}{\text { (Holdup) (Velocity) }}\right] \text {. }
$$

The first factor is the same as $\mathrm{Pi}(2)$. The second, with some reflection, states a defining relationship for velocity; the holdup times the velocity over the kiln length must equal the feed rate. With this realization, $\mathrm{Pi}(4)$ in this set becomes redundant.

Examination of the remaining eleven sets of Pi terms revealed many interesting combinations ot' the above groups, and each of the variables with the dimension of length was used as a basis for the dispersion number, fraction full, velocity number, and watt number, but no new groups were found.

The second step in the development of the analysis attempted to remove redundancy by eliminating all but one of each variable with identical 
TABLE 3. Pi terms from the general case with variables reordered

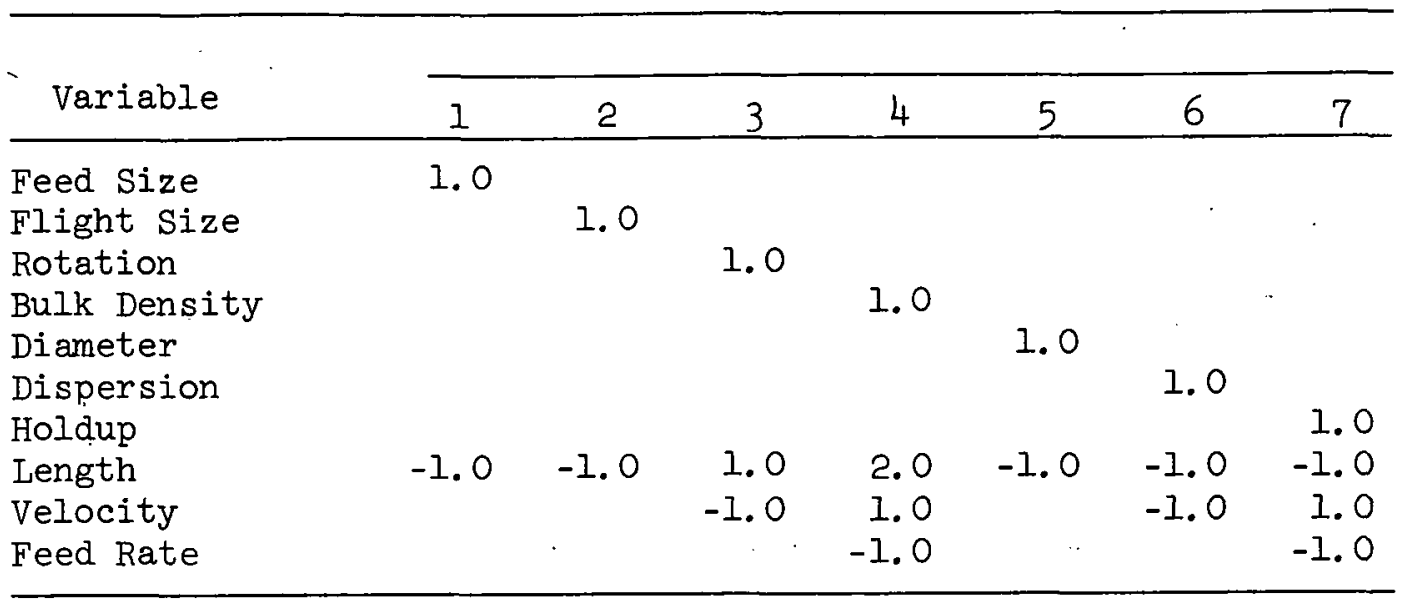

dimensions and by invoking all relationships derivable from external considerations. Thus, kiln length, feed size, and flight size were eliminated in favor of kiln diameter; holdup was given dimensions of mass per unit length. Velocity now equals the feed rate divided by holdup, and one of these variables can be eliminated. Tables 4 through 7 show two interesting cases in which the six remaining variables and three dimensions yield sets of three Pi terms.

In Tables 4 and 5, velocity was deleted in favor of holdup and feed rate. Two sets of $\mathrm{Pi}$ terms are shown. In the first set, $\mathrm{Pi}(1)$ is the reciprocal watt number and $\mathrm{Pi}(2)$ is the fraction full divided by the Watt number, and $\mathrm{Pi}(3)$ is the fraction full divided by the dispersion number, divided by the root of the Watt number. In the second set, $\mathrm{Pi}(1)$ is the reciprocal velocity number, $\mathrm{Pi}(2)$ is the reciprocal fraction full, and $\mathrm{Pi}(3)$ is the dispersion number.

In Tables 6 and 7, feed rate has been deleted in favor of velocity and holdup. For the first set, $\mathrm{Pi}(1)$ is the dispersion number divided by the velocity number, $\mathrm{Pi}(2)$ is the square of the dispersion number divided by the fraction full, and $\mathrm{Pi}(3)$ is the reciprocal of the dispersion number. For the second set, $\mathrm{Pi}(1)$ is the fraction full, $\mathrm{Pi}(2)$ is the watt number, and $\mathrm{Pi}(3)$ is the velocity number.

In summary, only three $\mathrm{Pi}$ terms are sufficient to describe this abbreviated system. For instance, the dispersion number should be a function 
TABLE 4. Dimensions of variables from the abbreviated case

\begin{tabular}{lccc}
\hline Variable & Mass & Length & Time \\
\hline Rotation & 0 & 0 & -1 \\
Bulk Density & 1 & -3 & 0 \\
Dispersion & 0 & 2 & -1 \\
Diameter & 0 & 1 & 0 \\
Holdup & 1 & -1 & 0 \\
Feed Rate & 1 & 0 & -1 \\
\hline
\end{tabular}

TARTF, 5. Pi terms from the abbreviated case

\begin{tabular}{|c|c|c|c|c|c|c|}
\hline \multirow[b]{2}{*}{ Variable } & \multicolumn{3}{|c|}{$\mathrm{Pi}($ Set 1$)$} & \multicolumn{3}{|c|}{$\mathrm{Pi}$ (Bet 2) } \\
\hline & $I$ & 2 & 3 & 1 & 2 & 3 \\
\hline Diameter & 1.0 & & & 1.0 & 2.0 & -1.0 \\
\hline Holdup & & 1.0 & & 1.0 & -1.0 & 1.0 \\
\hline Feed Rate & & & 1.0 & -1.0 & & -1.0 \\
\hline Rotation & 0.5 & 1.0 & 0.5 & $\overline{1} .0$ & & \\
\hline Bulk Density & & -1.0 & -1.0 & & 1.0 & \\
\hline Dispersion & -0.5 & -1.0 & -1.5 & & & 1.0 \\
\hline
\end{tabular}

TABLE 6. Dimensions of variables from the abbreviated case with variables reordered

\begin{tabular}{|c|c|c|c|c|}
\hline Variahle & Mass & & liength & Time \\
\hline Holdup & 1. & $\cdots$ & -1 & 0 \\
\hline Dispersion & 0 & & 2 & -1 \\
\hline Velocity & 0 & & 1 & -1 \\
\hline Rotation & 0 & & 0 & -1 \\
\hline Bulk Density & 1 & & -3 & 0 \\
\hline Diameter & $\overline{0}$ & & 1 & 0 \\
\hline
\end{tabular}


TABLE 7. Pi terms from the abbreviated case with variables ordered

\begin{tabular}{|c|c|c|c|c|c|c|}
\hline \multirow[b]{2}{*}{ Variable } & \multicolumn{3}{|c|}{ Pi (Set 1) } & \multicolumn{3}{|c|}{ Pi (Set 2) } \\
\hline & $\overline{1}$ & 2 & 3 & $\bar{I}$ & 2 & 3 \\
\hline Rotation & 1.0 & & & & -1.0 & -1.0 \\
\hline Bulk Density & & 1.0 & & -1.0 & & \\
\hline Diameter & & & 1.0 & -2.0 & -2.0 & -1.0 \\
\hline Holdup & & -1.0 & & 1.0 & & \\
\hline Dispersion & 1.0 & 2.0 & -1.0 & & 1.0 & \\
\hline Velocity & -2.0 & -2.0 & 1.0 & & & 1.0 \\
\hline
\end{tabular}

of the fraction full and the velocity number. Since the watt number in this abbreviated system is the dispersion number times the velocity number, some trivial combinations are possible. Normally, the dispersion number uses the length of the kiln and the Watt number uses the diameter.

Note that the $\mathrm{Pi}$ terms that are the ratios of lengths have not been included in this abbreviated case, but must be used in the correlation of experimental data.

\section{SIGNIFICANCE OF RESULTS}

The incentive for this study is to provide insight into the performance of rotary kilns as applied to the voloxidation process. In the analysis of the system as a chemical reactor and in the analysis of heat transfer to solids, the dispersion coefficient is an important term. This coefficient is a steady-state property of the system - a function of system design and operating variables - and although it is probably not a function of position, it is also defined at any point along the length of the kiln. It is appropriate, then, that length and hence axial position be eliminated from the variables, reducing the remainder to system means.

The dispersion coefficient can be included in a modified dispersion number or a Watt number, either of which is a function of the fraction full, the velocity number, and the set of $\mathrm{Pi}$ terms that represent the geometrical configuration of the system. This limitation in the degrees of freedom of the system is probably the most important conclusion of this study. 
Experimental program observations should now be considered. The velocity number, when divided by the operating slope of the kiln, becomes a dimensionless number (UNUM), which has been used to correlate data. The dimensionless number UNUM is essentially constant over a wide range of operating conditions; if it is a function of the fraction full, it is a weak effect. This dimensionless number does not seem to be a strong function of the feed size but probably depends upon the geometrical design of the kiln internals.

To the extent that UNUM is constant, the group that contains the dispersion coefificient is a function of only the fraction full and the geometrically derived $\mathrm{Pi}$ terms, which naturally include the term relating the feed size. Further, for the systems studied, the fraction full seems to have little effect over a reasonable range.

Since the Watt number or the modified dispersion number could be used to express the dispersion coefficient, a choice should be made. Because the Watt number shows less variation with experimental conditions and includes (in addition to the dispersion coefficient) only the rotational rate and the diameter, it is recommended over the modified dispersion number, that includes velocity, a variable not directly measurable.

\section{A DIFFEREIVT PROBLEM}

The task of explaining or even correlating the dispersion coefficient as a steady-state system property is not to be confused with the task of measuring it. The most convenient method for measuring the dispersion coefficient is a transient method that takes concentration data on the effluent stream from an operating kiln subjected to an input change. The results are interpreted by comparison with predictions from a mathematical model that consists of a fundamental partial differential equation and one of several sets of boundary conditions. The dimensionless groups required for this study come directly from the differential equation. Where possible, this is a better method for establishing relevent Pi terms than the Buckingham $P i$ method. In this case, the Pi terms included a dimensionless time, a dimensionless concentration, and a dispersion number based on kiln length. These Pi terms could have been obtained by the Buckingham Pi method. 
Replacing rotation with time, holdup with concentration (using M/L for dimensions), and diameter with length in Table 4 yields a different set of terms (Table 5). However, this problem is not the same as the problem addressed in the text of this paper. Different sets of Pi terms are necessary to accommodate different purposes. 
THIS PAGE

\section{WAS INTENTIONALLY LEFT BLANK}


ORNL/TM- 5898

\section{INTERNAL DISTRIBUTION}

\begin{tabular}{|c|c|c|}
\hline 1. & J. E. & Bigelow \\
\hline 2. & R. E. & Blanco \\
\hline 3. & J. 0. & Blomeke \\
\hline & W. D. & Bond \\
\hline 5. & B. F. & Bottenfield \\
\hline 6. & R. E. & Brooksbank \\
\hline 7-11. & W. D. & Burch \\
\hline 12. & D. $\mathrm{O}$. & Campbell \\
\hline 13. & J. M. & Chandler \\
\hline 14. & W. E. & Clark \\
\hline 15. & D. J. & Crouse \\
\hline 16. & F. L. & Culler \\
\hline 17. & M. J. & Feldman \\
\hline 18. & L. M. & Ferris \\
\hline 19. & E. H. & Gift, ORGDP \\
\hline 20. & R. W. & Glass \\
\hline 21. & J. H. & Goode \\
\hline 22. & N. R. & Grant \\
\hline-27. & W. S. & Groenier \\
\hline 28. & D. C. & Hampson \\
\hline 29. & D. W. & Holladay \\
\hline 30. & W. D. & Holland \\
\hline 31. & D. E. & Horner \\
\hline 32. & A. $R$. & Irvine \\
\hline 33. & A. D. & Kelmers \\
\hline 34. & I. J. & King \\
\hline 35. & R. E. & Leuze \\
\hline 36. & B. E. & Lewis \\
\hline 37. & R. A. & Lorenz \\
\hline & J. C. & Mailen \\
\hline
\end{tabular}

39. A. P. Malinauskas

40. E. L. Nicholson

41. K. J. Notz

42. A. R. Olsen

43. F. L. Peishel

44. Herman Postma

45. R. H. Rainey

46. A. D. Ryon

47. H. C. Savage

48. C. D. Scott

49. B. B. Spencer

50. M. J. Stephenson, ORGDP

51. D. B. Trauger

52. W. E. Unger

53. V. C. A. Vaughen

54-58. B. L. Vondra

59. C. D. Watson

60. B. S. Weil

61. T. D. Welch

62-71. M. E. Whatley

72. S. K. Whatley

73. R. G. Wymer

74. 0. O. Yarbro

75. Central Research Library

76. ORNL - Y-12 Technical Library Document Research Section.

77-78. Laboratory Records

79. Laboratory Records, ORNL R. C.

80. ORNL Patent Office

81. Nuclear Safety Information Center

\section{EXTERNAL DISTRIBUTION}

82. H. M. Agnew, Director, Los Alamos Scientific Laboratory, P. 0. Box 1663, Los Alamos, NM 87545

83. T. W. Ambrose, Director, Pacific Northwest Laboratory, P. 0. Box 999, Richland, WA 99352

84. Argonne National Laboratory, P. O. Box 2528, Idaho Falls, ID 83401

85. Argonne National Laboratory, 9700 South Cass Avenue, Argonne, II 60439

86. Battelle-Columbus Laboratories, 505 King Avenue, Columbus, OH 43201

87. R. M. Bernero, Chief, Fuel Reprocessing and Recycle Branch, Division of Fuel Cycle and Material Safety, United States Nuclear Regulatory Commission, Washington, D. C. 20555 
88-89. H. J. Groh, Director, Environmental Sciences Section, E. I. du Pont de Nemours \& Company, Savannah River Laboratory, Aiken, SC 29801

90. R. I. Dickeman, President, Bxxon Nuclear Compary, Inc., 777 106th Avenue, NE, Bellevue, WA 98004

91-92. A. S. Jennings, Separations Chemistry \& Engineering Section, E. I. du Pont de Nemours \& Company, Savannah River Laboratory, Aiken, SC 29801

93. M. L. Hyder, Separations Chemistry \& Engineering Section, E. I. du Pont de Nemours \& Company, Savannah River Laboratory, Aiken, SC 29801

94. Hanford Engineering Development Laboratory, Associate Lab Director, P. O. Box 1970, Richland, WA 99352

95-96. J. L. Crandall, Director, Nuclear Engineering \& Materials Section, E. I. du Pont de Nemours \& Company, Savannah River Laboratory, Aiken, SC 29801

97. T. B. Hindman, Jr., Director, Fuel Cycle Project office, U.S. Energy Research and Jevelopment Administration, Savannah River Operations Office, P. O. Box A, Aiken, SC 29801

98. P. Hogroian, Division of Nuclear Fuel Cycle and rroduction, U.S. Energy Research and Development Administration, Washington, DC 20545

99. L. H. Myer, Program Manager, Technical nivision, E. I. du Pont de Nemours and Company, Aiken, SC 29801

100. C. Kuhlman, Division of Nuclear Fuel Cycle and Production, U.S. Energy Research and Development Administration, Washington, DC 20545

101. J. A. Kyger, Associate Director, Argonne National Laboratory, 9700 South Cass Avenue, Argonne, IL 60439

102. H. E. Lyon, Division of Safeguards and Security, U. S. Energy Research and Development Administration, Weshington, DC 20545

103. R. I. Newman, Vice-President, Allied-General Nuclear Services, P. O. Bux 847, Barnwell, sC 29812

104. N. F. Slevering, Jr., Assistant Administrator for International Affairs, U.S. Energy Research and Development Administration, Washington, DC 20545

105. D. Spurgeon, Division of Nuclear Fuel Cycle and Production, U.S. Energy Research and Devel npment. Administration, Waohington, DC 20545

106. A. Squire, virector, Hanford Engineering Development Laboratory, P. 0. Box 1970, Richland, WA 99352

107. N. Stetson, Manager, U.S. Energy Research and Development Administration, Savannah River Operations Office, P.O. Box A, Aiken, SC 29801

108. K. Slrcet, Associate Directur, Luwrence Rádiation Laboratory, P. 0. Box 808, Livermore, CA 94550

109. D. S. Webster, Argonne National Laboratory, Building 205, 9700 South Cass Avenue, Argonne, II 60439

110. U. S. Energy Research and Development Administration, Chicago Uperations Ut'lice, Contracts Division, 9800 South Cass Avenue, Argonne, IL 60439

111. U. S. Energy Research and Development Administration, Division of RDD, Energy Systems Analysis, Washington, DC 20545 
112. U. S. Energy Research and Development Administration, Division of RDD, Engineering and Technology, Washington, DC 20545

113. U. S. Energy Research and Development Administration, Division of RDD, IMFBR Programs, Washington, DC 20545

114. U. S. Energy Research and Development Administration, Division of RDD, Reactor Safety, Washington, DC 20545

115. U. S. Energy Research and Development Administration, Library, Washington, DC 20545

116. U. S. Energy Research and Development Administration, Research and Technical Support Division, P. O. Box E, Oak Ridge, TN 37830

117. U. S. Energy Research and Development Administration, Oak Ridge Operations Office, Reactor Division, P. O. Box E, Oak Ridge, TN 37830

118. U. S. Energy Research and Development Administration, Patent Office Washington, DC 20545

119. U. S. Energy Research and Development Administration, Richland Operations Of'ice, P. O. Box 550; Richland, WA 99352

120. U. S. Energy Research and Development Administration, Southern California Energy Program Office, P. O. Box 1446, Canoga Park, CA 91304

121. U. S. Energy Research and Development Administration, Technical Information Center, Qak Ridge, TN 37830

122. U. S. Energy Research and Development Administration, Division of Reactor Development Demonstration, Washington, DC 20545

123. U. S. Energy Research and Development Administration, Idaho Operations office, 550 and Street, Idaho Falls, ID 83401

124. U. S. Energy Research and Development Administration, Nevada Operations office, P. O. Box 14100, Las Vegas, NV 89114

125. U. S. Energy Research and Development Administration, San Francisco Operations Office, 1333 Broadway, Wells Fargo Building, Oakland, CA 94612 